\title{
ASSESSING THE ACCURACY OF SHALLOW WATER DEPTH ESTIMATION BY USING MULTISPECTRAL SATELLITE IMAGES
}

\author{
Ratna Sari DEWI'*(D), Aldino RIZALDY', Prayudha HARTANTO' (i), \\ and Suprajaka SUPRAJAKA ${ }^{1}$
}

DOI: 10.21163/GT_2021.163.14

\begin{abstract}
:
Timely and accurate bathymetry information is needed to support an effective policy on utilization and management of coastal natural resources. Satellite derived bathymetry (SDB) has been widely considered as an advanced and low-cost method for shallow water depth estimation. This is due to the availability of multi-temporal and multi-resolution satellite data. This study focuses on evaluating the accuracy of satellite derived bathymetry derived from multispectral images recorded by various sensors with various spatial resolution. The study area is located in a small island nearby Morotai Island, Indonesia. Four SDB models were compared. The implementation of the SDB model was carried out by combining echo-sounding measurements and the reflectance of blue, green, red, and near infrared bands of three satellite images (World View 2, Sentinel 2A and Landsat 8). Our findings reveal that all three satellite images performed well in assessing SDB at various spatial and spectral resolution, however, the use of high-resolution imagery did not always improve accuracy, for example when using SVM (Support Vector Machine). When using RF (Random Forest), Sentinel 2A produced the best accuracy and when using GAM (Generalized Additive Model), the most feasible result was generated only by using WorldView 2 image. In all cases, RF performed well and provided the most accurate SDB prediction.
\end{abstract}

Key-words: Bathymetry, Depth, Satellite-derived bathymetry, Multispectral images, Morotai.

\section{INTRODUCTION}

Indonesia as one of the countries with the longest coastline in the world requires an efficient coastal management. In order to support effective policy on utilization and management of coastal natural resources, timely and accurate information such as bathymetry information is needed (Pacheco et al., 2015). Accurate satellite derived bathymetry is considered of fundamental aspect towards monitoring sea floor and deriving nautical charts to support marine navigation. Furthermore, an accurate bathymetry information is necessary to develop shoreline and terrain model, basis data for hydrodynamic modelling, water sediment monitoring, water quality, reconnaissance survey and coral reef monitoring (Hartmann, Wettle and Heege, 2017; Chybicki, 2018).

Remote sensing technology has been widely used to provide shallow water depth information (Brando et al., 2009), because of availability of multi-temporal and multi-resolution satellite data. In addition, remote sensing technique is more efficient in terms of time and budget due to its capability to cover large areas (Cahalane et al., 2019; Kumari and Ramesh, 2020; Zhang et al., 2021). Various methods have been adopted for acquiring shallow water depth information. Conventional methods for i.e., ship-borne echo sounding measurements has restriction in a very shallow area due to safety reason (Pattanaik, Sahu and Bhutiyani, 2015). Meanwhile, LIDAR as an optical remote sensing technique can produce highly accurate measurements. However, LIDAR measurement over an area is also very expensive (Kanno et al., 2013; Kumari and Ramesh, 2020). To overcome those limitation, satellite derived bathymetry (SDB) has been used to estimate the nearshore bathymetry (Philpot, 1989; Stumpf, Holderied and Sinclair, 2003; Kanno et al., 2013; Chénier, Faucher and Ahola, 2018).

\footnotetext{
${ }^{1}$ Geospatial Information Agency of Indonesia (Badan Informasi Geospasial), *Corresponding Author ratna.sari@big.go.id; aldino.rizaldy@big.go.id; prayudha.hartanto@big.go.id; suprajaka@big.go.id
} 
Multiple algorithms have been proposed to develop the SDB models by using single band (Gholamalifard et al., 2013) and multispectral bands (Vinayaraj, Raghavan and Masumoto, 2016; Chénier, Faucher and Ahola, 2018; Sagawa et al., 2019). The SDB algorithms fall into two broad categories: analytical and empirical method. The analytical method works based on the ability of light to penetrate water which requires inputs of various parameters of atmosphere, water column and bottom material (Green et al., 2000). Obtaining the atmosphere and water properties is difficult and requires large samples from field measurement (Gao, 2009). Therefore, the empirical model has become an alternative method since it requires fewer parameters such as training data from echo sounding measurement. The empirical method was implemented based on the relationship between the reflectance of water recorded by sensor and the water depth at sampled locations (Gao, 2009; Hartmann, Wettle and Heege, 2017; Vinayaraj, 2017).

This research focuses on assessing the performance of four SDB algorithms in extracting shallow water depth information by using three different sensors. The methods namely GAM (Generalized Additive Model), MLR (Multiple Linear Regression), SVM (Support Vector Machine) and RF (Random Forest) were tested in small islands located in the southwest of Morotai Island, Indonesia. Three sensors namely: WorldView 2, Sentinel 2A and Landsat 8 OLI/TIRS were used, and several studies have reported the use of each sensors (Chénier, Faucher and Ahola, 2018; Traganos et al., 2018; Sagawa et al., 2019). In this study, comparisons between four SDB techniques as well as accuracy assessments using available bathymetric data were done in order to identify approaches that have the best performance given the environmental conditions of the study site at the time of image acquisition. We used multiple spatial and spectral resolutions to investigate their influences on the accuracy of bathymetry models. Thus, the objectives of this study can be summarized as follows:

a. To determine the best SDB model for each satellite product through four SDB algorithms.

b. To compare GAM, MLR, SVM and RF for their SDB prediction accuracies together with the significance of each model's parameter found from objective (a).

\section{METHODOLOGY}

\subsection{Study area}

The SDB models were implemented over shallow water area of small islands located in the southwest of Morotai Island, North Moluccas Province, Indonesia (Fig. 1). The central point of the study area is at geographical coordinates $2^{\circ} 7^{\prime} 30^{\prime \prime} \mathrm{N}$ and $128^{\circ} 13^{\prime} 23^{\prime \prime} \mathrm{E}$. The small islands are part of the administrative area of Galo-galo Village. Waters in Galo-galo Village is generally clear with visibility around $10 \mathrm{~m}$ (Ismail, 2007). The bottom is composed of sand, seagrass and life coral (Wijaya et al., 2012; S. Halim, 2017).

\subsection{Remote sensing dataset}

Images used in this study are listed in Tab. 1, consisting of WorldView 2, Sentinel 2A and Landsat 8 OLI/TIRS with 2, 10 and $30 \mathrm{~m}$ spatial resolution. The WorldView 2 image was obtained from Indonesia Geospatial Information Agency (BIG) in Ortho Ready Standard (OR2A) product. The product is radiometrically corrected and sensor corrected (DigitalGlobe, 2013). Meanwhile, the Sentinel 2A image was in the Level-2A product and obtained from the Copernicus Open Access (ESA et al., 2018). The available product has undergone a standard radiometric and geometric corrections (ESA, 2015). The third image used is Landsat 8 OLI/TIRS which was obtained freely from USGS Earth Explorer (USGS, 2019). For this image, the surface reflectance format was used and a standard radiometric and geometric corrections has been implemented by the provider (USGS, 2015). In addition, for extracting shallow water depth information, four spectral bands were used as in Tab. 1. All bands were in visible and near infrared bands. 


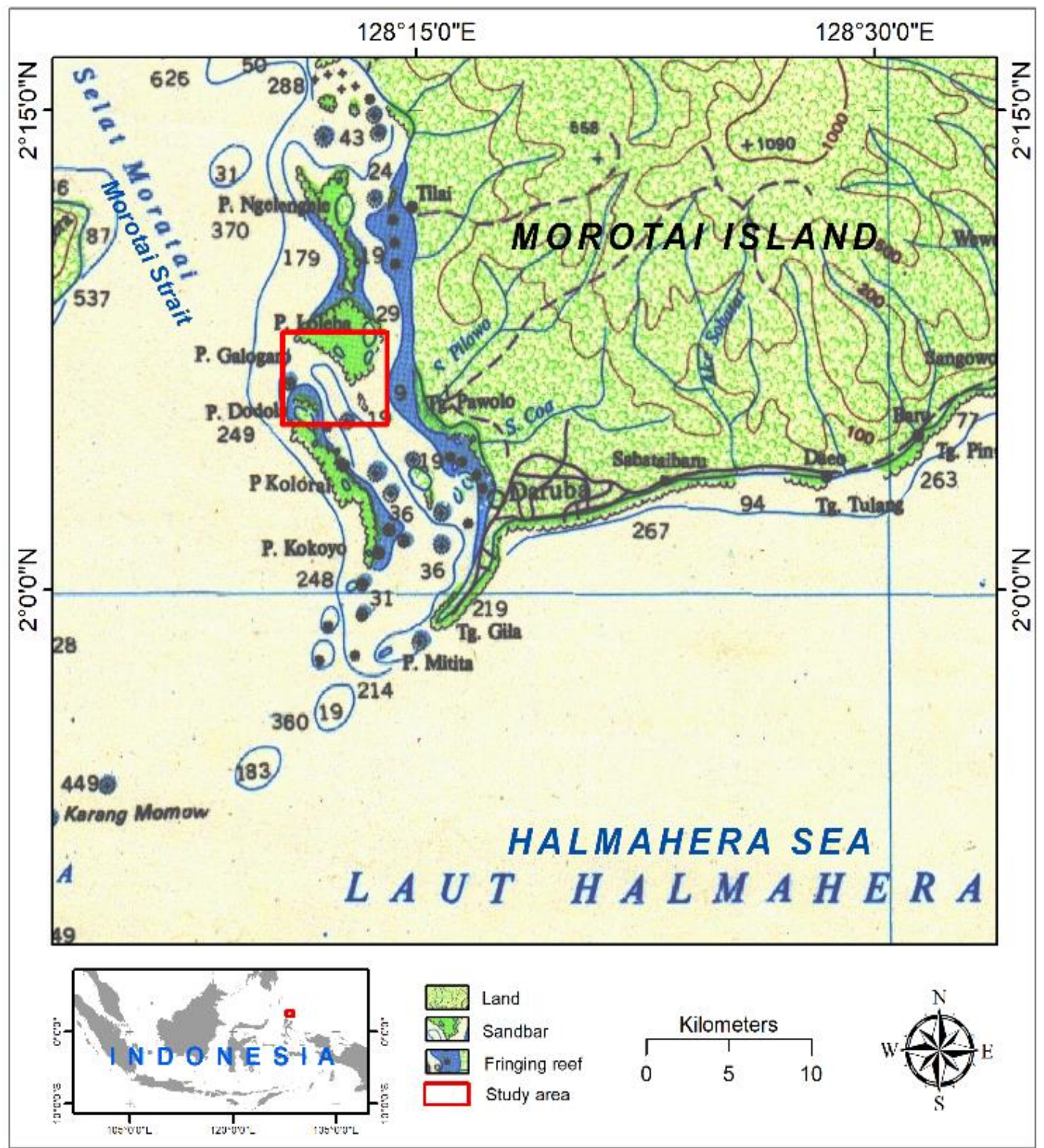

Fig. 1. Study area in small islands located at the southwest of Morotai Island, North Moluccas Province, Indonesia. Red rectangle shows the study area location. The National Marine Environmental Map is used as the background.

Table 1.

Input images for the SDB model in this study.

\begin{tabular}{|c|c|c|c|}
\hline Images & Acquisition Date & Resolution (m) & Product format \\
\hline WorldView 2 & March 31 ${ }^{\text {st }}, 2013$ & 2 & Ortho Ready Standard \\
\hline Sentinel 2A & May 21 ${ }^{\text {st }}, 2019$ & 10 & Level-2A \\
\hline Landsat 8 OLI/TIRS & February $20^{\text {th }}, 2019$ & 30 & Surface Reflectance \\
\hline
\end{tabular}




\subsection{Bathymetry data}

For Morotai Island and surroundings, the best data available from the Indonesia Geospatial Information Agency's survey database were multibeam and single beam echosounder surveys completed in August 2018. All datasets were corrected for zero tidal influences by BIG. In this case, the depth measured by echosounder was corrected by adding or subtracting a tidal height which was derived from hourly tide predictions (Bramante, Raju and Sin, 2013; Siermann et al., 2014). These tide prediction data were obtained from the nearest tide gauge station, namely: Jailolo Tide Gauge Station in Halmahera Island, North Moluccas Province. Therefore, for this study, no additional tidal correction is needed as the SDB relationships are based on tide-corrected data. The depth information from the Single Beam Echo Sounder (SBES) ranges from $3 \mathrm{~m}$ up to $30 \mathrm{~m}$. Tab. 2 summarizes the number of measurement points available within $3 \mathrm{~m}$ depth ranges.

Table 2.

Number of measurement points within $\mathbf{2} \mathbf{m}$ depth ranges for hydrographic data.

\begin{tabular}{ccccccc}
\hline Overall & $0-3 \mathrm{~m}$ & $3-6 \mathrm{~m}$ & $6-9 \mathrm{~m}$ & $9-12 \mathrm{~m}$ & $12-15 \mathrm{~m}$ & $15-30 \mathrm{~m}$ \\
\hline 62,150 & N/A & 35,007 & 7,421 & 4,353 & 2,490 & 12,879 \\
\hline
\end{tabular}

In this research, two scenarios were set for the selection of training data to be included in the SDB model. In the first scenario, we selected randomly $20 \%$ of training data from the SBES measurements points, and the remaining $80 \%$ for the accuracy assessment of the SDB model. Meanwhile, in the second scenario, $80 \%$ of training data from the SBES points were selected as training data, and $20 \%$ for the accuracy assessment of the SDB model.

\subsection{Image pre-processing}

\subsubsection{Geometric correction}

Before the implementation of the SDB algorithm, geo-referencing was implemented to all images. Geo-registration of images (Sentinel-2A and Landsat 8 OLI/TIRS) was conducted using geometrically corrected reference image, namely a WorldView- 2 image at $2 \mathrm{~m}$ spatial resolution. The spectral band information for each image is available in Tab. 3. For each image, we created dataset consists of four bands in blue, green, red, and near infrared bands (visible plus near infrared/NIR bands).

Table 3.

The spectral band information of images used in this research.

\begin{tabular}{ccc|ccc}
\hline Satellite & Bands & Wavelength $(\boldsymbol{\mu m})$ & Satellite & Bands & Wavelength $(\boldsymbol{\mu m})$ \\
\hline \multirow{5}{*}{ WorldView-2 } & Blue & $0.45-0.51$ & & Blue & 0.49 \\
& Green & $0.51-0.58$ & Sentinel 2 & Green & 0.56 \\
& Red & $0.58-0.62$ & Red & 0.66 \\
& Near-IR1 & $0.63-0.69$ & SWIR & 0.66 \\
\hline \multirow{5}{*}{ Landsat 8 OLI/TIRS } & Blue & $0.45-0.51$ & & \\
& Green & $0.53-0.59$ & & \\
& Red & $0.64-0.67$ & & \\
& NIR & $0.85-0.88$ & & & \\
\hline
\end{tabular}




\subsubsection{Image correction}

Fig. 2 provides an illustration of spectral reflectance $\left(L_{s}\right)$ in shallow water observed by a sensor consisting of: atmospheric scattering $\left(\lambda_{\mathrm{a}}\right)$, reflection of sea surface $\left(L_{\mathrm{r}}\right)$, in-water scattering $\left(L_{\mathrm{w}}\right)$, and bottom reflection $\left(L_{b}\right)$ (Kanno, Koibuchi and Isobe, 2011; Vinayaraj, Raghavan and Masumoto, 2016). The recorded spectral reflectance $\left(L_{s}\right)$ is estimated by a function of wavelength as:

$$
L_{s}=L_{a}+L_{r}+L_{w}+L_{b}
$$

In this study, image correction was performed based on the averaged deep water area (Lyzenga, 1981; Spitzer and Dirks, 1987; Gholamalifard et al., 2013) for removal of scattering in the atmosphere and external reflection from water surface. The methods assumed that in deep water, there is no bottom reflectance element in the spectral radiance observed by the sensor. Number of pixels were sampled from deep water and their average radiance value (DN) was then subtracted from all pixels in every band respectively (Green et al., 2000):

$$
L=L_{i}-L_{s i}
$$

where $L_{\mathrm{i}}$ is the measured reflectance in shallow water for band $i$ and $L_{\mathrm{si}}$ is the average reflectance for deep water in band $i$.

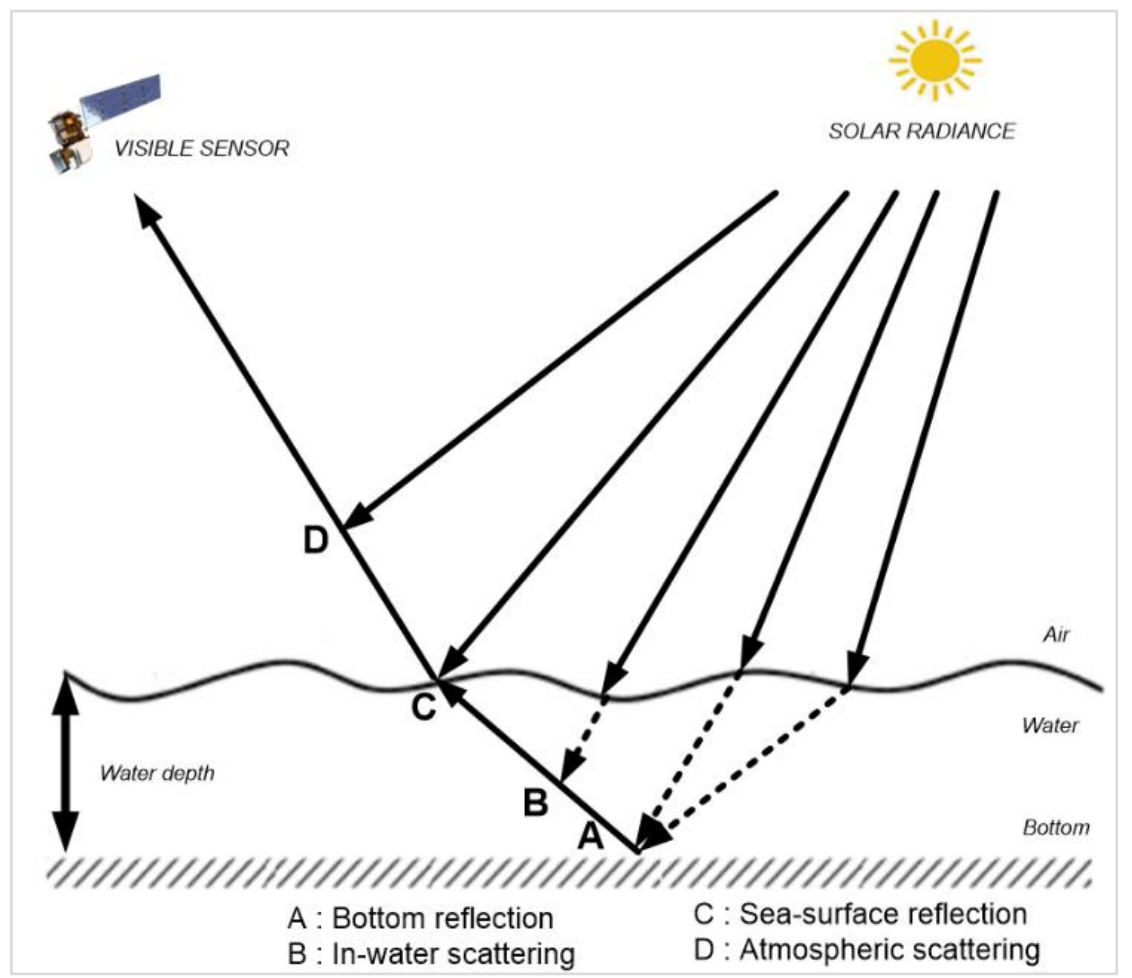

Fig. 2. The visualization of spectral reflectance components recorded by sensor in water area (modified from Kanno, 2011). 


\subsubsection{Linearize relationship between depth and pixel reflectance}

In relatively clear water, light intensity will decline exponentially with the increasing depth. In this step, the value of light intensity (reflectance) were transformed using natural logarithms $(\ln )$. The relationship between light intensity and depth becomes linear, and therefore the transformed reflectance values decrease linearly with the increasing depth as written as follows (Green et al., 2000; Gholamalifard et al., 2013):

$$
X_{i}=\ln \left(L_{i}-L_{s i}\right)
$$

where $X_{\mathrm{i}}$ is the transformed reflectance values of a pixel in band $i, L_{\mathrm{si}}$ is the average reflectance for deep water in band $i$.

\subsection{Modeling of Bathymetry}

\subsubsection{Semi-parametric regression using spatial coordinates (GAM)}

The GAM method is a combination of Lyzenga's method (Lyzenga, 1978) and spatial interpolation method. Kanno (2011) developed the method using semi-parametric regression which models the error term in Lyzenga's method based on its spatial dependency. The formula can be written as (Kanno, Koibuchi and Isobe, 2011):

$$
h_{z}=\mathrm{X} \delta+t(\varphi)+\varepsilon^{\prime}
$$

where $\mathrm{X}$ and $\delta$ are the Lyzenga's estimators derived from SBES measurements and visible band of images. Meanwhile, $t(\varphi)$ is a smooth nonparametric function of the two-dimensional coordinate vector $\varphi$ and $\varepsilon^{\prime}$ is a random variable with a zero mean. When solving the equation, a penalized thinplate regression spline was used. It is included in the 'mgcv' package, specifically the Generalized Additive Model (GAM) smoothing function. This package is available in the $\mathrm{R}$ programming language. In addition, we used the smooth term function ' $\mathrm{s}$ ' that was improved using Generalized Cross Validation (GCV) and regression 'splines' with fixed degrees of freedom in this experiment. The definition of this degree of freedom, expressed as $k$, is a crucial step in adopting the SDB model. According to Wood (2017), the value of $k$ should be neither too large nor too small. We used different $k$ numbers in this experiment, such as $100,200,400,600,800$, and 1000. The RMSE value produced by the model was used to evaluate the results. For further detailed descriptions of this algorithm are available in Wood (2017).

\subsubsection{Multiple Linear Regressions (MLR)}

Linear regression models the relationship between dependent and independent variables. If there is only one independent variable it is called simple linear regression, while in the case of more than one independent variable it is called multiple linear regression (MLR). The relationships are modeled by linear functions and the parameter are estimated from the data. Due to its simplicity, MLR has been extensively used for predicting bathymetry data in the shallow water area from multi spectral bands of satellite imagery (Clark, Fay and Walker, 1987; Hamilton et al., 1993).

This method assumes that the bottom reflectance and water composition are constant within all part of the image (Van Hengel, 1991). Therefore, this method might work since the bottom reflectance affects multi spectral bands of the imagery. In the case of predicting bathymetry data from multi spectral bands, the dependent variable is the bathymetry depth $\left(W_{z}\right)$ while the independent variables 
are the transformed radiance from multi spectral bands $\left(X_{n}\right)$. In order to estimate the parameters of MLR, echo sounding surveys were conducted in the area as the dependent variable $W_{z}$. Then the estimated parameters are used to predict the bathymetry depth from the transformed radiance (independent variables). This method is formally described as follow (Van Hengel and Spitzer, 1991):

$$
W_{z}=\beta_{0}+\beta_{1} X_{1}+\beta_{2} X_{2}+\cdots+\beta_{n} X_{n}+\varepsilon
$$

where $W_{z}$ is bathymetry depth, $\beta_{0}$ is the intercept, $\beta_{1}, \beta_{2}, \ldots, \beta_{n}$ are the slopes, $n$ is the number of spectral bands, and $\varepsilon$ is the error term. MLR works by estimating $\beta$ such that $\varepsilon$ is minimized.

\subsubsection{Support Vector Machine (SVM)}

SVM, as one of machine learning algorithm, can do both classification and regressions. In this study, the SVM-based regression was used to model the relation between training data i.e., depth measurement data and the transformed reflectance from satellite images. The accuracy of the SVMbased regression is usually determined by the appropriate selection of kernel and its parameters (Gao, 2015; Misra et al., 2018). From literature, Gao (2009) suggested that the radial basis function (RBF) has a good performance in predicting depth in the Great Lakes. Therefore, in this research, we also applied RBF kernel when performing SVM.

In this study, we determined various values of the smoothing parameter $\gamma$, as the parameter of RBF kernel, it controls the shape of the "peaks" and defines the inverse of the influence radius of sample selected as support vectors. In this case low value of $\gamma$ representing 'far' influence while high values meaning 'close' influence. The SVM model has been implemented in R software by using the package "e1071". For this experiment, we set various $\lambda$ values (equal to $0.01,0.1,1,10$, and 100) and a standard cost parameter of SVM.

\subsubsection{Random Forest $(R F)$}

RF, like SVM, is one of machine learning algorithm that can do both classification and regressions (Breiman, 2001). In this research, the RF regression model was used to model the relationship between the water depth data from echo sounding measurement (response variable) and transformed reflectance data from images (predictor variable) (McLaren, McIntyre and Prospere, 2019; Sagawa et al., 2019). The RF model works by creating a random sample from our training data with a similar distribution for all trees and estimating depth based on these tree correlations.

For this study, we used "random Forest" package in R environment. We set a various value for ntree parameter for i.e., 100, 300, 500, 700 and 1000 that represent number of trees to grow for the decision tree estimates. Meanwhile, we keep default values for the other hyperparameters, such as mtry (number of variables randomly sampled as candidates at each split), sampsize (size of sample to draw), nodesize (minimum size of terminal nodes), maxnodes (maximum number of terminal nodes trees in the forest can have).

\subsection{Accuracy Assessment of the SDB models}

The SDB models were evaluated by estimating the Root Mean Square Error (RMSE) shown in Equation 6. For the accuracy assessment purposes, we used SBES points as testing data based on different scenarios that have been set. 


$$
R M S E=\sum \sqrt{\frac{\left(Z_{i}-Z_{i}^{\prime}\right)^{2}}{\mathrm{~N}}}
$$

where $Z_{i}$ is the actual depth value from in-situ measurement data, $Z_{i}^{\prime}$ is the expected value of SDB, and $N$ is the number of elements in the data.

\section{RESULTS AND DISCUSSIONS}

\subsection{Generalized adaptive model}

Obviously, applying various $k$ values only slightly changed the RMSE values (see Fig. 3 and Tab. 4) both by using $20 \%$ and $80 \%$ of training data from the SBES measurement points. When using $20 \%$ training data, the RMSE values ranged from $2.60-2.65 \mathrm{~m}$ with $R^{2}$ ranged from $0.88-0.89$ for Landsat 8 OLI/TIRS, $2.44-2.46 \mathrm{~m}$ with $R^{2}$ ranged from $0.893-0.894$ for Sentinel 2A, and $1.11-$ $1.80 \mathrm{~m}$ with $R^{2}$ ranged from $0.94-0.98$ for WorldView 2. Meanwhile when increasing the number of training data into $80 \%$, the RMSE values were from $2.60-2.65 \mathrm{~m}$ with $R^{2}$ ranged from $0.878-$ 0.884 for Landsat 8 OLI/TIRS, $2.44-2.45 \mathrm{~m}$ with $R^{2}$ ranged from $0.889-0.89$ for Sentinel $2 \mathrm{~A}$, and $1.05-1.76 \mathrm{~m}$ with $R^{2}$ ranged from $0.94-0.98$ for WorldView 2. In general, the increasing training data ratios only produced little differences in accuracies of the SDB model. Moreover, by using Landsat OLI/TIRS, the increasing training data caused the decreasing of accuracy of the model showing by the decreasing of the $R^{2}$ value.

From both results in Fig. 3, we can also see that setting higher $k$ did not always provide a better accuracy. Moreover, higher $k$ required a longer processing time to execute the models. The highest accuracy values when using Landsat 8 OLI/TIRS and Sentinel 2A were obtained when setting $k=$ 200 while when using WorldView $2, k=1000$ provided the best accuracy.

The visualization of those models is available in Fig. 4. The SDB models resulted from Landsat 8 and Sentinel 2A were clearly over smoothing comparing to the model resulted from WorldView 2. The experiments revealed that we cannot rely solely on the RMSE values of the predicted result, but it is critical to check the SDB models visually. The experiment concluded that the SDB model by using GAM may be more suitable to be applied for higher resolution image such as WorldView 2 which has $2 \mathrm{~m}$ spatial resolution which was supported by the lowest RMSE value obtained (1.054 $\mathrm{m})$.
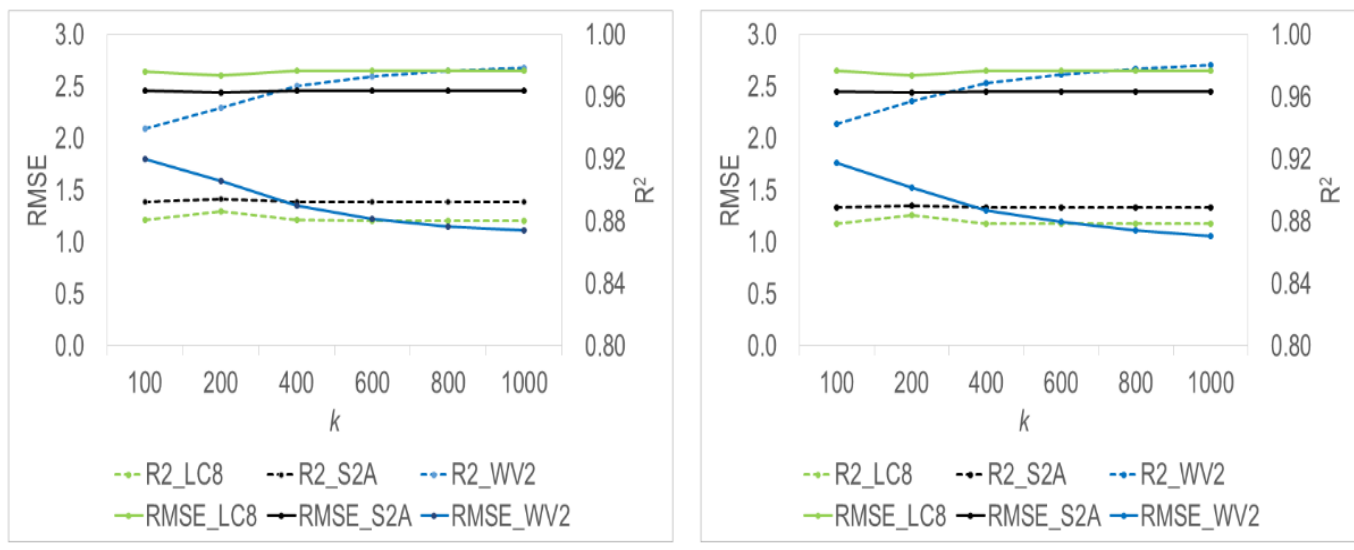

Fig. 3. The RMSE and $R^{2}$ values when applying GAM with training data ratio $20 \%$ (left) and $80 \%$ (right). Dashed-lines show the coefficient correlation values $R^{2}$ while solid lines represent RMSE values. Four bands were used by comparing three images from three sensors, namely WV2=Worldview-2, S2A=Sentinel 2A, and LC8=Landsat 8 OLI/TIRS. 
Table 4.

The results of accuracy assessment of the SDB model using GAM.

\begin{tabular}{cccccccc}
\hline \multirow{2}{*}{ Datasets } & \multirow{2}{*}{$\boldsymbol{R}^{\mathbf{2}}$ and RMSE (m) } & \multicolumn{7}{c}{$k$} \\
\cline { 3 - 8 } a) Training ratio: 20\% & & $\mathbf{1 0 0}$ & $\mathbf{2 0 0}$ & $\mathbf{4 0 0}$ & $\mathbf{6 0 0}$ & $\mathbf{8 0 0}$ & $\mathbf{1 0 0 0}$ \\
\hline \multirow{2}{*}{ LC8 } & $R^{2}$ & 0.88 & 0.89 & 0.88 & 0.88 & 0.88 & 0.88 \\
& RMSE & 2.64 & 2.60 & 2.65 & 2.65 & 2.65 & 2.65 \\
\hline \multirow{2}{*}{ S2A } & $R^{2}$ & 0.89 & 0.89 & 0.89 & 0.89 & 0.89 & 0.89 \\
& RMSE & 2.46 & 2.44 & 2.46 & 2.46 & 2.46 & 2.46 \\
\hline \multirow{2}{*}{ WV2 } & $R^{2}$ & 0.94 & 0.95 & 0.97 & 0.97 & 0.98 & 0.98 \\
& RMSE & 1.80 & 1.59 & 1.34 & 1.22 & 1.15 & 1.11 \\
\hline \multirow{2}{*}{ b) Training ratio: 80\% } & & & & & & & \\
\hline \multirow{2}{*}{ LC8 } & $R^{2}$ & 0.88 & 0.88 & 0.88 & 0.88 & 0.88 & 0.88 \\
& RMSE & 2.65 & 2.60 & 2.65 & 2.65 & 2.65 & 2.65 \\
\hline \multirow{2}{*}{ S2A } & $R^{2}$ & 0.89 & 0.89 & 0.89 & 0.89 & 0.89 & 0.89 \\
& RMSE & 2.45 & 2.44 & 2.45 & 2.45 & 2.45 & 2.45 \\
\hline \multirow{2}{*}{ WV2 } & $R^{2}$ & 0.94 & 0.96 & 0.97 & 0.97 & 0.98 & 0.98 \\
& RMSE & 1.76 & 1.52 & 1.30 & 1.19 & 1.11 & 1.05 \\
\hline \multirow{2}{*}{} & & & & & & &
\end{tabular}

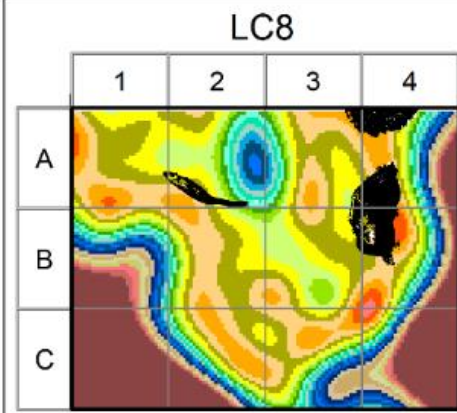

(a)

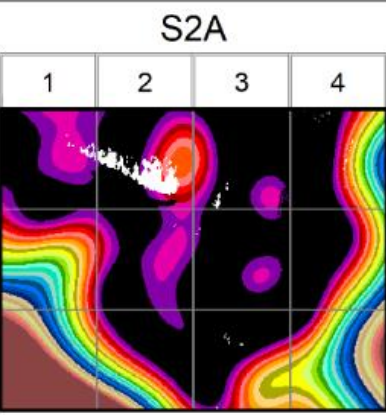

(b)

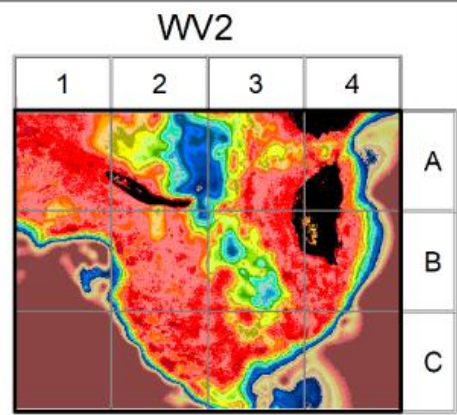

(c)
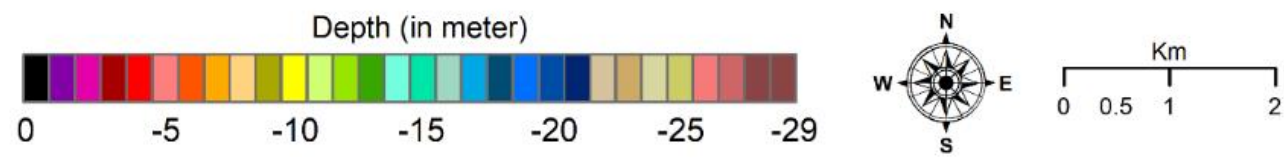

Fig. 4. The visualization of SDB model when applying GAM for: (a) Landsat 8 OLI/TIRS ( $k=200$ ); (b) Sentinel 2A $(k=200)$; and (c) WorldView $2(k=1000)$ images. WorldView 2 presents the best visualization of the results with higher $k$ produced less noisy results. Black pixels represent land area while white pixels indicated no data. For image notations, see the caption of Fig. 3.

\subsection{Support Vector Machine results interpretation}

Setting two training ratios when applying SVM greatly influenced the SDB models as can be seen in Fig. 5 and Tab. 5. When using 20\% training data, the RMSE values ranged from $1.59-2.96$ $\mathrm{m}$ with $R^{2}$ ranged from $0.86-0.96$ for Landsat 8 OLI/TIRS, $1.56-4.47 \mathrm{~m}$ with $R^{2}$ ranged from 0.63 
- 0.96 for Sentinel 2A, and $1.56-5.47 \mathrm{~m}$ with $R^{2}$ ranged from $0.52-0.96$ for WorldView 2 . Meanwhile when increasing the number of training data into 80\%, the RMSE values were from 1.15 $-2.88 \mathrm{~m}$ with $R^{2}$ ranged from $0.86-0.98$ for Landsat 8 OLI/TIRS, $1.09-2.31 \mathrm{~m}$ with $R^{2}$ ranged from $0.91-0.98$ for Sentinel 2A, and $1.470-3.80 \mathrm{~m}$ with $R^{2}$ ranged from $0.77-0.96$ for WorldView 2. Setting higher proportion of training data resulted in better accuracies of the SDB model. The increasing training data ratios produced large differences in accuracies of the SDB model implying that the SVM was highly dependent on the amount of training data. It is critical to have a large amount of training data. The accuracies of the SDB model obtained in this study, especially when using Sentinel 2A, was worse than the accuracies obtained by the previous study by Mateo-Perez et al., (2020) that was able to achieve RMSE values of 0.3-0.4 m. Meanwhile, Misra et al., (2018) by using Landsat image obtained RMSE values of $2.88 \mathrm{~m}$ which was quite similar with our results.
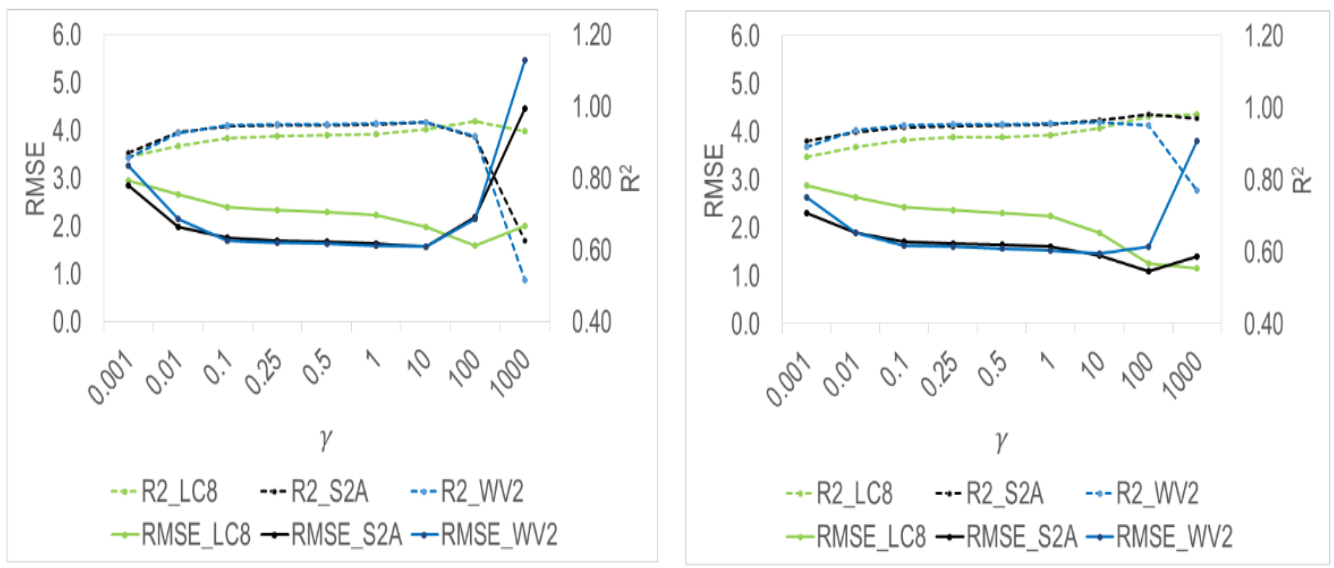

Fig. 5. The RMSE and $R^{2}$ values when applying SVM with training data ratio $20 \%$ (left) and $80 \%$ (right). For image notations, see the caption of Fig. 3.

Table 5.

The results of accuracy assessment of the SDB model using SVM

\begin{tabular}{|c|c|c|c|c|c|c|c|c|c|c|}
\hline \multirow{2}{*}{ Datasets } & \multirow{2}{*}{$\begin{array}{c}R^{2} \text { and } \\
\operatorname{RMSE}(\mathbf{m})\end{array}$} & \multicolumn{9}{|c|}{$\lambda$} \\
\hline & & 0.001 & 0.01 & 0.1 & 0.25 & 0.5 & 1 & 10 & 100 & 1000 \\
\hline \multicolumn{11}{|c|}{ a) Training ratio: $20 \%$} \\
\hline \multirow{2}{*}{ LC8 } & $R^{2}$ & 0.86 & 0.89 & 0.91 & 0.92 & 0.92 & 0.92 & 0.94 & 0.96 & 0.93 \\
\hline & RMSE & 2.96 & 2.66 & 2.40 & 2.32 & 2.28 & 2.23 & 1.98 & 1.59 & 2.01 \\
\hline \multirow{2}{*}{ S2A } & $R^{2}$ & 0.87 & 0.93 & 0.94 & 0.95 & 0.95 & 0.95 & 0.96 & 0.91 & 0.63 \\
\hline & RMSE & 2.85 & 1.99 & 1.75 & 1.70 & 1.67 & 1.64 & 1.56 & 2.18 & 4.47 \\
\hline \multirow{2}{*}{ WV2 } & $R^{2}$ & 0.86 & 0.92 & 0.95 & 0.95 & 0.95 & 0.95 & 0.96 & 0.92 & 0.52 \\
\hline & RMSE & 3.25 & 2.14 & 1.70 & 1.66 & 1.64 & 1.60 & 1.56 & 2.15 & 5.47 \\
\hline \multicolumn{11}{|c|}{ b) Training ratio: $80 \%$} \\
\hline \multirow{2}{*}{ LC8 } & $R^{2}$ & 0.86 & 0.89 & 0.91 & 0.92 & 0.92 & 0.92 & 0.94 & 0.98 & 0.98 \\
\hline & RMSE & 2.88 & 2.63 & 2.44 & 2.36 & 2.31 & 2.25 & 1.89 & 1.26 & 1.15 \\
\hline \multirow{2}{*}{ S2A } & $R^{2}$ & 0.91 & 0.93 & 0.95 & 0.95 & 0.95 & 0.95 & 0.96 & 0.98 & 0.97 \\
\hline & RMSE & 2.31 & 1.90 & 1.71 & 1.66 & 1.64 & 1.61 & 1.42 & 1.09 & 1.41 \\
\hline \multirow{2}{*}{ WV2 } & $R^{2}$ & 0.89 & 0.94 & 0.95 & 0.95 & 0.95 & 0.96 & 0.96 & 0.95 & 0.77 \\
\hline & RMSE & 2.63 & 1.89 & 1.64 & 1.61 & 1.57 & 1.53 & 1.47 & 1.61 & 3.80 \\
\hline
\end{tabular}


Applying various $\gamma$ values contributed to changing in the RMSE of the SDB models (see Fig. 5) both by using $20 \%$ and $80 \%$ of training data from the SBES measurement points. From both results in Fig. 5, in general, by using Landsat 8 OLI/TIRS, Sentinel 2A and WorldView 2, a lower RMSE value was obtained by increasing $\gamma$. When setting $20 \%$ training data, the best models were achieved with values of $\gamma$ equal to 100 and 10 for Landsat OLI/TIRS, and both Sentinel 2A and WorldView, respectively. Meanwhile, by setting training data into 80\%, the best SDB models were resulted from $\gamma$ values equal to 1000, 100 and 10 for Landsat OLI/TIRS, Sentinel 2A and WorldView, respectively. The visualization of those models is available in Fig. 6. The SDB model from Landsat 8 OLI/TIRS was clearly noisy while SDB models from Sentinel 2A and WorldView 2 depict a much more representative depth distribution, especially in shallow water area.

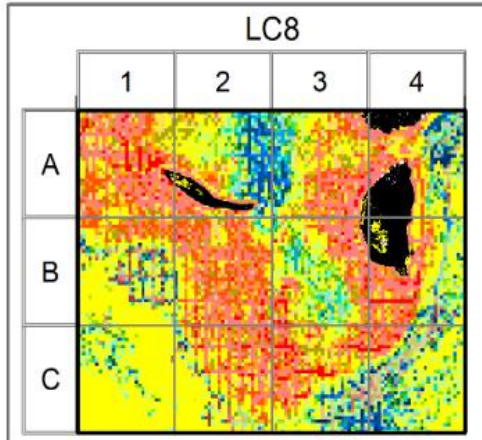

(a)

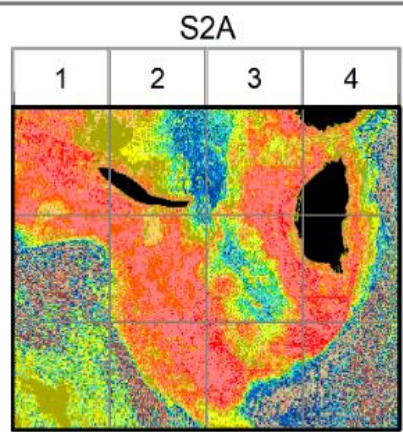

(b)

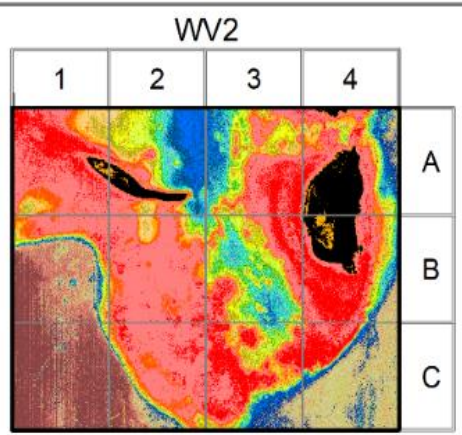

(c)

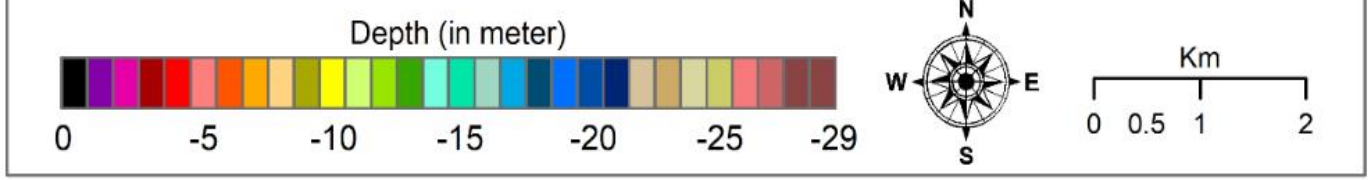

Fig. 6. The visualization of the best SDB model when applying SVM for: (a) Landsat 8 OLI/TIRS ( $\gamma=$ 1000); (b) Sentinel 2A $(\gamma=100)$; and (c) WorldView $2(\gamma=10)$ images. Black pixels represent land area while white pixels indicated no data. For image notations, see the caption of Fig. 3.

\subsection{Multi Linear Regression results interpretation}

Applying MLR with various training ratios had little influence on the SDB results. Moreover, increasing training data from $20 \%$ to $80 \%$ reduced the quality of the SDB model showed by the increase of the RMSE values, except when using WorldView 2. By using WorldView, there was a little decrease of the RMSE from 2.626 to $2.608 \mathrm{~m}$ (see Tab. 6).

WorldView-2 with $80 \%$ training data produced the best accuracy with $R^{2}$ equal to 0.871 and RMSE value equal to 2.608. SDB model using Landsat 8 OLI/TIRS outperformed WorldView 2 with RMSE equal to 2.431 and $2.442 \mathrm{~m}$ with $R^{2}$ equal to 0.888 and 0.886 for $20 \%$ and $80 \%$ training data, respectively. For this case, a higher image resolution did not result in a better SDB model in terms of RMSE values. When we compared the results obtained from this study with other previous studies, for example when using WorldView 2 datasets, Jawak and Luis (2015) could obtained higher accuracy with RMSE value of $0.21 \mathrm{~m}$. However, in their study, 8 bands of WorldView 2 were included for the implementation of SDB model. In this case, the number and type of bands that were used may have influenced the model accuracy (Manessa et al., 2016). 
Table 6

The validation results obtained by comparing predicted and observed value of depths. Asterisk notifies the lowest RMSE value.

\begin{tabular}{cccc}
\hline Datasets & Training Ratio & $\boldsymbol{R}^{\mathbf{2}}$ & RMSE (m) \\
\hline \multirow{2}{*}{ LC8 } & $20 \%$ & 0.888 & $2.431^{*}$ \\
& $80 \%$ & 0.886 & 2.442 \\
\hline \multirow{2}{*}{ S2A } & $20 \%$ & 0.858 & 2.893 \\
& $80 \%$ & 0.853 & 2.934 \\
\hline \multirow{2}{*}{ WV2 } & $20 \%$ & 0.869 & 2.626 \\
& $80 \%$ & 0.871 & 2.608 \\
\hline
\end{tabular}

Fig. 7 presents the comparisons of the SDB models resulted from MLR applied using three different images showing that MLR were able to represent depth distribution consistently. The variation of training data and the spatial resolution of images did not produce large influences on the predicted SDB results as when using GAM method.

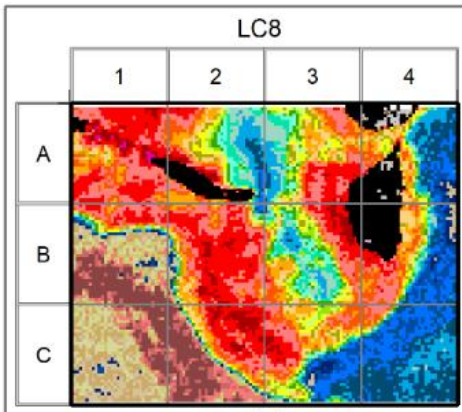

(a)

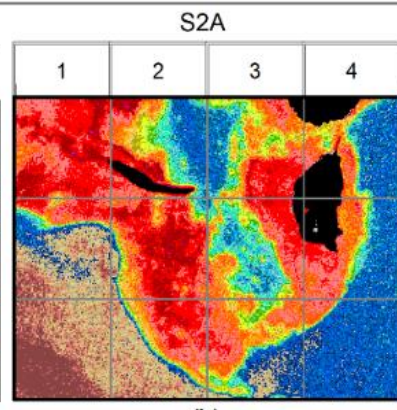

(b)

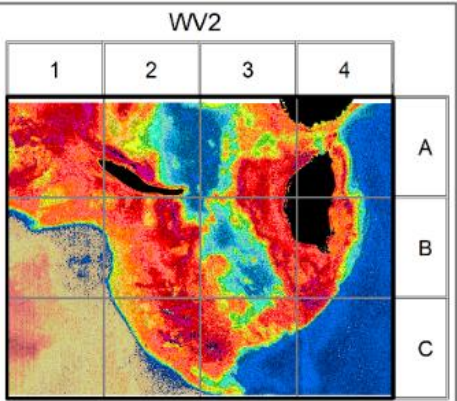

(c)
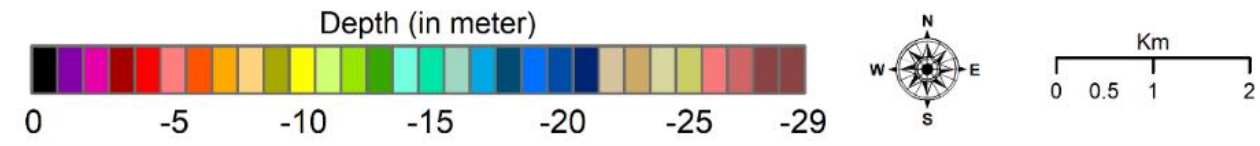

Fig. 7. The visualization of SDB model when applying MLR with $80 \%$ of training data for: (a) Landsat 8 OLI/TIRS; (b) Sentinel 2A; and (c) WorldView 2 images. Black pixels represent land area while white pixels indicated no data. For image notations, see the caption of Fig. 3.

\subsection{Random Forest results interpretation}

As SVM, setting two training ratios when applying RF also largely influenced the SDB models as can be seen in Fig. 8 and Tab. 7. When using 20\% training data, the RMSE values ranged from $1.097-1.099 \mathrm{~m}$ with $R^{2}$ equal to 0.981 for Landsat 8 OLI/TIRS, $1.265-1.272 \mathrm{~m}$ with $R^{2}$ equal to 0.973 for Sentinel $2 \mathrm{~A}$, and $1.442-1.456 \mathrm{~m}$ with $R^{2}$ equal to 0.960 for WorldView 2. Meanwhile when increasing the number of training data into $80 \%$, the RMSE values were $0.934 \mathrm{~m}$ with $R^{2}$ equal to 0.987 for Landsat 8 OLI/TIRS, $0.667-0.670 \mathrm{~m}$ with $R^{2}$ equal to 0.993 for Sentinel 2A, and 1.204 $-1.210 \mathrm{~m}$ with $R^{2}$ equal to 0.972 for WorldView 2. Setting higher proportion of training data resulted in better accuracies of the SDB model. The increasing training data ratios produced large differences in accuracies of the SDB model especially for Landsat OLI/TIRS and Sentinel 2A. It was implying that the RF was highly dependent on the amount of training data like SVM and having large amount of training data was important as has been suggested by Sagawa et al., (Sagawa et al., 2019). 
Fig. 8 shows little variation of RMSE values when applying RF by varying the $n$ tree values both by using variation in training set ratio. It was implying that variation of ntree has little influence on the prediction results. Moreover, applying larger ntree values corresponded to the longer time needed for the SDB model.

The visualization of RF models is available in Fig. 9. The SDB model from Landsat 8 OLI/TIRS was a little bit noisy while SDB models from Sentinel 2A and WorldView 2 depict a much more representative depth distribution, especially in shallow water area. Similarly, with MLR method, a higher image resolution did not result in a better SDB model in terms of RMSE values.

Table 7.

The results of accuracy assessment of the SDB model using RF.

\begin{tabular}{ccccccc}
\hline \multirow{2}{*}{ Datasets } & $\begin{array}{c}\boldsymbol{R}^{2} \text { and } \\
\mathbf{R M S E}(\mathbf{m})\end{array}$ & $\mathbf{1 0 0}$ & $\mathbf{3 0 0}$ & $\mathbf{5 0 0}$ & $\mathbf{7 0 0}$ & $\mathbf{1 0 0 0}$ \\
\cline { 3 - 7 } a) Training ratio: 20\% & & & & ntree \\
\hline \multirow{2}{*}{ LC8 } & $R^{2}$ & 0.98 & 0.98 & 0.98 & 0.98 & 0.98 \\
& $\mathrm{RMSE}$ & 1.10 & 1.10 & 1.10 & 1.10 & 1.10 \\
S2A & $R^{2}$ & 0.97 & 0.97 & 0.97 & 0.97 & 0.97 \\
& $\mathrm{RMSE}$ & 1.27 & 1.27 & 1.27 & 1.27 & 1.27 \\
\multirow{2}{*}{ WV2 } & $R^{2}$ & 0.96 & 0.96 & 0.96 & 0.96 & 0.96 \\
& $\mathrm{RMSE}$ & 1.46 & 1.44 & 1.44 & 1.44 & 1.44
\end{tabular}

b) Training ratio: $80 \%$

\begin{tabular}{ccccccc}
\hline \multirow{2}{*}{ LC8 } & $R^{2}$ & 0.99 & 0.99 & 0.99 & 0.99 & 0.99 \\
& RMSE & 0.93 & 0.93 & 0.93 & 0.93 & 0.93 \\
\hline \multirow{2}{*}{ S2A } & $R^{2}$ & 0.99 & 0.99 & 0.99 & 0.99 & 0.99 \\
& RMSE & 0.67 & 0.67 & 0.67 & 0.67 & 0.67 \\
\hline \multirow{2}{*}{ WV2 } & $R^{2}$ & 0.97 & 0.97 & 0.97 & 0.97 & 0.97 \\
& RMSE & 1.21 & 1.21 & 1.21 & 1.20 & 1.20 \\
\hline
\end{tabular}

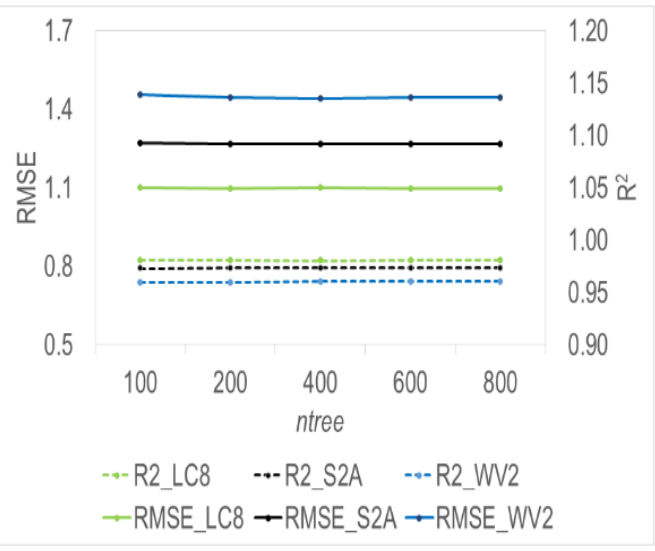

(a)

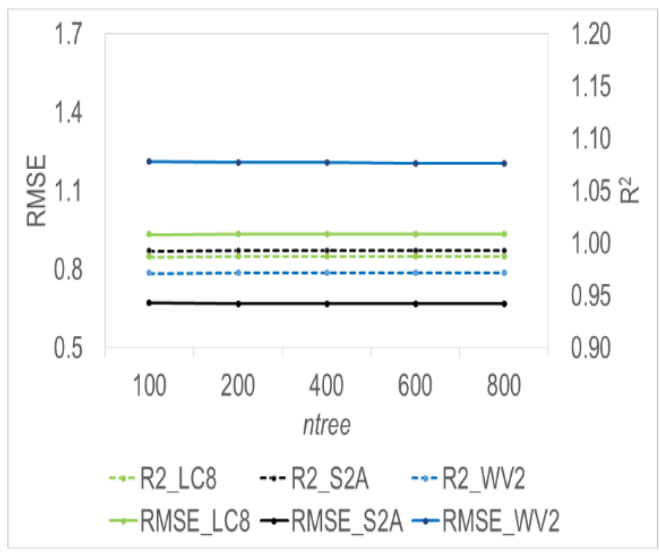

(b)

Fig. 8. The RMSE and $R^{2}$ values when applying RF with training data ratio $20 \%$ (a) and $80 \%$ (b). For image notations, see the caption of Fig. 3. 


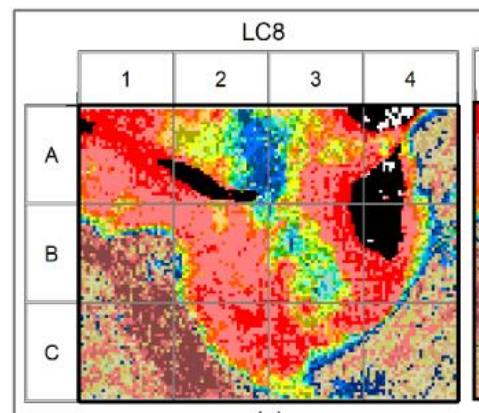

(a)

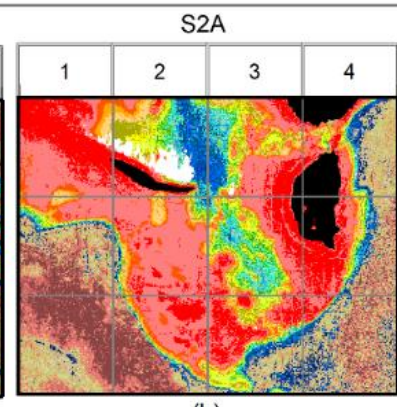

(b)

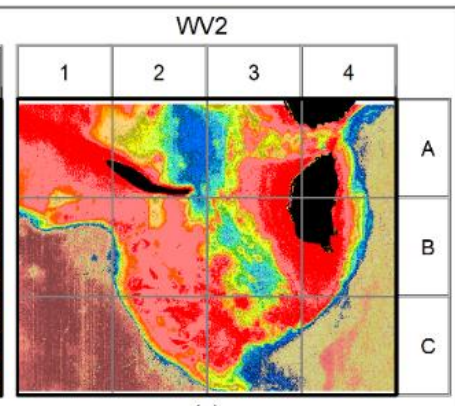

(c)
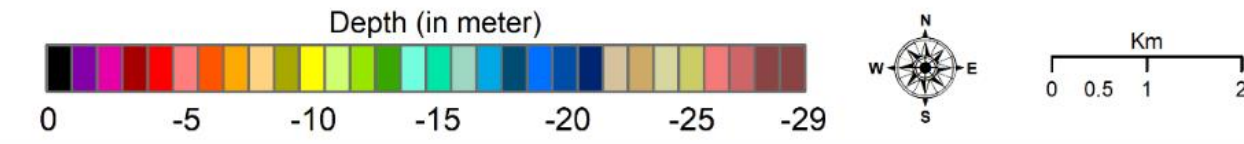

Fig. 9. The visualization of SDB model when applying RF with $80 \%$ of training data and $n t r e e=500$ for: (a) Landsat 8 OLI/TIRS; (b) Sentinel 2A; and (c) WorldView 2 images. Black pixels represent land area while white pixels indicated no data. For image notations, see the caption of Fig. 3.

\subsection{Comparison of the Models}

A comparison of bathymetric profiles of the four SDB models with combination of multibeam and single-beam measurement data by using three different images is provided in Fig. 10 - 12. By using Worldview 2 images (see Fig. 10), SDB model from RF had the best fit with the measurement data which was supported by higher accuracies of RF model approximately $1 \mathrm{~m}$ (see Fig. 8b). In shallow water area of less than $5 \mathrm{~m}$, all the SDB models were also in a good agreement with the measurement data. However, in deeper area from 5-10 m, MLR significantly overestimate the water depth (see Fig. 8c and Fig. 9c for e. g. gridlines B3, C1 and C2). This was supported by low accuracies given by MLR approximately $2.6 \mathrm{~m}$ (see Tab. 5). This result was in line with the previous study conducted by Manessa et al., (2016) that RF performed better compared to the MLR.

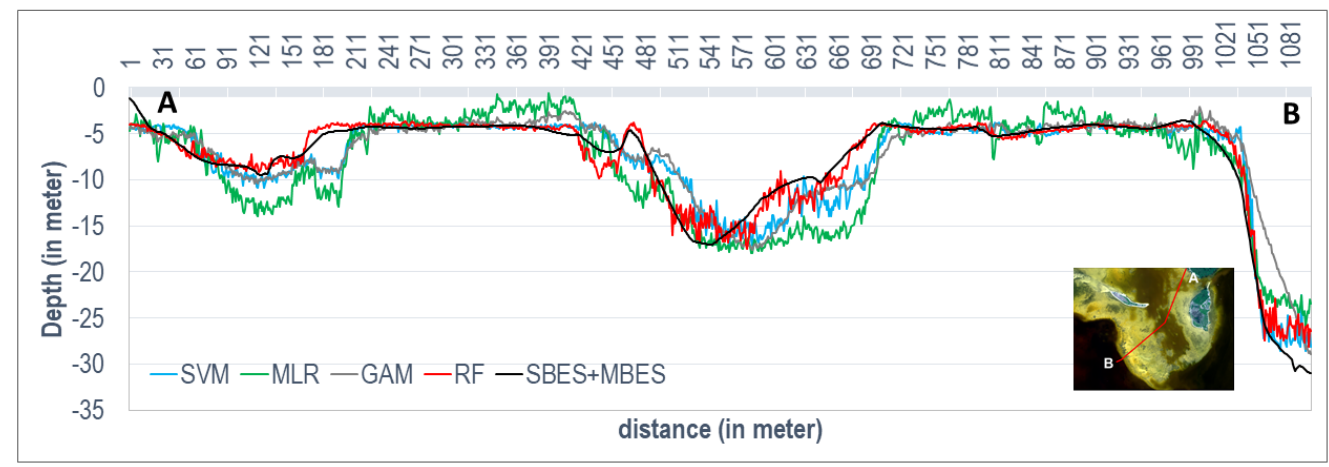

Fig. 10. Transect showing a comparison between the four SDB models and measurement data developed by using WorldView 2. The transects starts from point A to point B.

Fig. 11 presents bathymetry profile of four SDB models by using Sentinel 2A showing that all SDB models except GAM were in a good agreement in shallow water area less than $5 \mathrm{~m}$. GAM model provided a flattened curve shifting away from the other models. Fig. $\mathbf{4 b}$ shows that large portion of shallow water was predicted as land area (see black pixels). From the profile in Fig. 11, RF model obviously had the best fit with the measurement data supported by higher accuracies of RF model approximately $0.67 \mathrm{~m}$ (see Fig. 8b). Meanwhile, SVM and MLR made errors by producing deeper depth prediction between 5-15 m. 


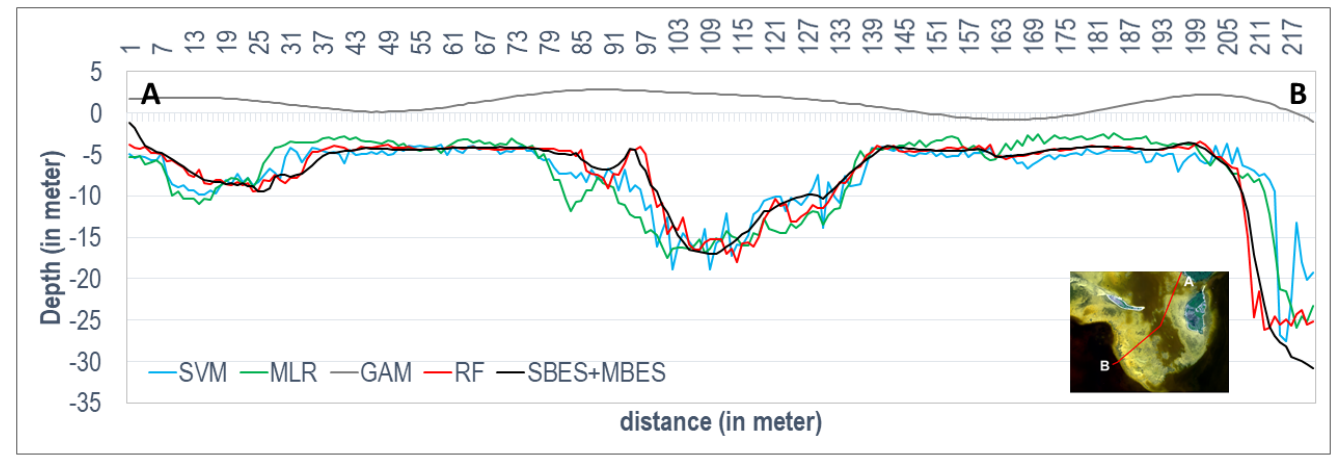

Fig. 11. Transect showing a comparison between the four SDB models and measurement data developed by using Sentinel $2 \mathrm{~A}$. The transects starts from point A to point B.

Bathymetric profiles when using Landsat OLI/TIRS image are available in Fig. 12. SDB model from RF and MLR fit quite well with the measurement data. It was supported by higher accuracies of RF model approximately $1 \mathrm{~m}$ (see Fig. 8) and $2.4 \mathrm{~m}$ for MLR (see Tab. 4). Meanwhile, the bathymetry profiles of SDB model from SVM fluctuated irregularly. GAM model provided a flattened curve shifting away from the other models.

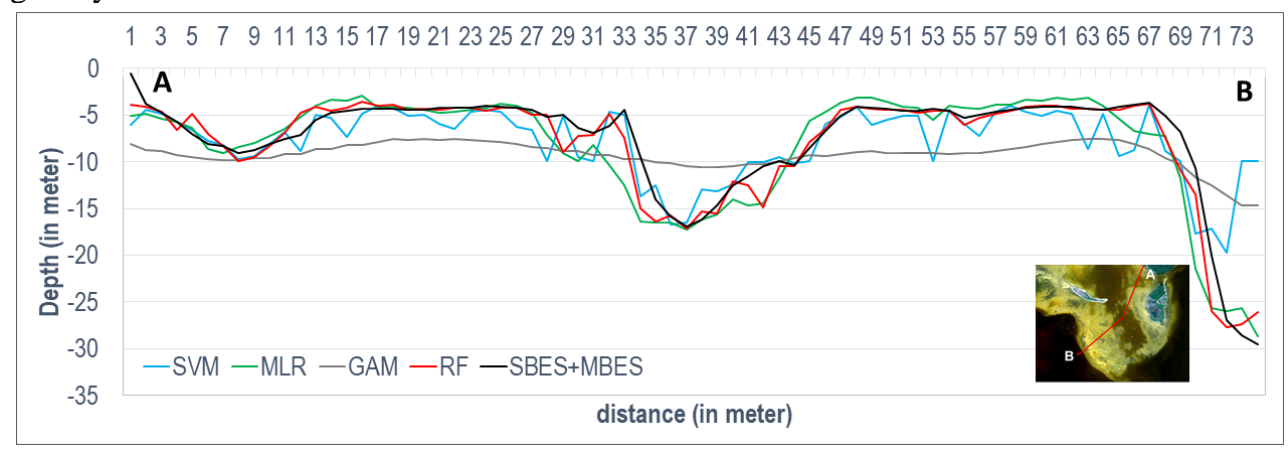

Fig. 12. Transect showing SDB models derived from Sentinel $2 A$ when applying GAM (green), SVM (yellow), MLR (blue) compared to 2018 survey.

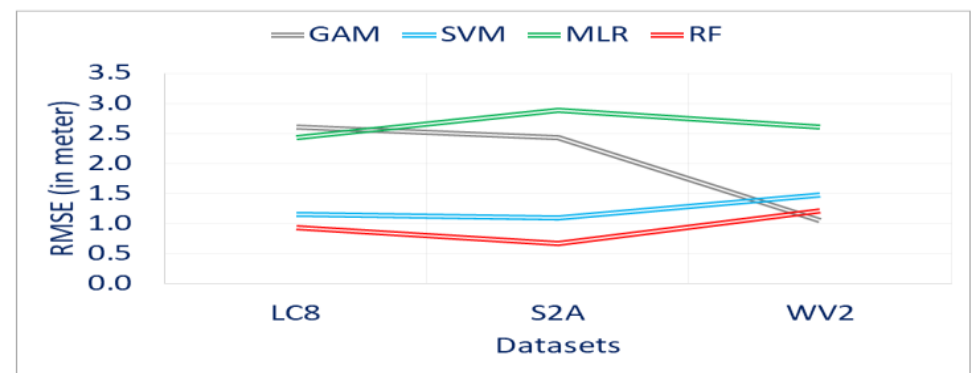

Fig. 13. Accuracy comparisons of the SDB models used by using Landsat OLI/TIRS, Sentinel 2A and WorldView 2.

Fig. 13 shows the performance of each SDB model by using three different images. RF shows consistencies of the best performance. Meanwhile GAM method provided the best accuracy only when using WorldView 2. MLR method provided the largest RMSE errors implying of the most inaccurate model. 


\section{CONCLUSIONS}

In this paper, we compared four methods for satellite derived bathymetry by using three different image resolutions. We also checked the influence of training and testing ratio to the models. In general, by increasing the number of training data, the SDB models obtained higher accuracies. However, when using MLR algorithm with Sentinel 2A and Landsat 8 OLI/TIRS images, increasing the number of training data led to a slight decrease of the accuracies.

Among the four algorithms, SVM and RF were highly influenced by the number of training data used. As also has been mentioned by Sagawa et al., (Sagawa et al., 2019) that a large amount of training data is important for the implementation of machine learning-based SDB algorithm. Not only the amount of the training data but also their coverage is critical. SVM and RF perform poorly when extrapolating beyond the range of the training data set. So it is important to have a slightly wider depth area (Geyman and Maloof, 2019; Sagawa et al., 2019) for the training dataset.

All three satellite imageries provided meaningful results to assess SDB accuracy at various spatial and spectral resolution. However, in this research, the use of high-resolution imagery did not always improve accuracy, for example when using SVM. The accuracy of SVM model by using Landsat 8 OLI/TIRS image was better than the accuracy of SVM model when using Sentinel 2A and World View 2. In addition, when using RF, Sentinel 2A produced the best accuracy. However, when using GAM model, the most feasible result was generated only by using World View 2 image. In all cases, $\mathrm{RF}$ performed well and provided the most accurate SDB prediction.

\section{ACKNOWLEDGEMENTS}

The authors would like to thank our colleagues from the Center for Marine and Coastal Environment Mapping of the Geospatial Information Agency for providing data, insight and expert inputs that greatly assisted this research. This research was jointly funded by the Indonesia Geospatial Information Agency and the Ministry of Research and Technology/National Agency for Research and Innovation of Indonesia, via Research Incentive Program of National Innovation System 2021, Research Incentive Implementation Contract Ref. 1/INS/PPK/E4/2021.

\section{R E F E R E N C E S}

Bramante, J. F., Raju, D. K. and Sin, T. M. (2013) 'Multispectral derivation of bathymetry in Singapore' s shallow, turbid waters' International Journal of Remote Sensing, 34(6), pp. 2070-2088. doi: 10.1080/01431161.2012.734934.

Brando, V. E. et al. (2009) 'A physics based retrieval and quality assessment of bathymetry from suboptimal hyperspectral data', Remote Sensing of Environment, 113(4), pp. 755-770. doi: 10.1016/j.rse.2008.12.003.

Breiman, L. (2001) 'Random Forests' , Machine Learning, 45(1), pp. 5-32. doi: 10.1023/A:1010933404324.

Cahalane, C. et al. (2019) 'A comparison of Landsat 8, RapidEye and Pleiades products for improving empirical predictions of satellite-derived bathymetry' , Remote Sensing of Environment, 233(111414), p. 15. doi: 10.1016/j.rse.2019.111414.

Chénier, R., Faucher, M.-A. and Ahola, R. (2018) 'Satellite-Derived Bathymetry for Improving Canadian Hydrographic Service Charts' , ISPRS International Journal of Geo-Information, 7(8), p. 306. doi: 10.3390/ijgi7080306.

Chybicki, A. (2018) 'Three-Dimensional Geographically Weighted Inverse Regression (3GWR) Model for Satellite Derived Bathymetry Using Sentinel-2 Observations’ , Marine Geodesy, 41(1), pp. 1-23. doi: 10.1080/01490419.2017.1373173.

Clark, R. K., Fay, T. H. and Walker, C. L. (1987) 'Bathymetry calculations with Landsat 4 TM imagery under a generalized ratio assumption’ , Applied Optics, 26(19), pp. 4036_1-4038. doi: 10.1364/AO.26.4036_1. 
DigitalGlobe (2013) Base Product Series FAQ.

ESA (2015) 'SENTINEL-2 User Handbook’ , Sentinel-2 User Handbook.

ESA et al. (2018) 'Sentinel-2 Products Specification Document' , Thales Alenia Space.

Gao, J. (2009) 'Bathymetric mapping by means of remote sensing: methods, accuracy and limitations' , Progress in Physical Geography: Earth and Environment, 33(1), pp. 103-116. doi: 10.1177/0309133309105657.

Gao, S. (2015) Shallow Water Depth Inversion Based on Data Mining Models. Louisiana State University and Agricultural and Mechanical College. Available at: https://digitalcommons.lsu.edu/gradschool_theses/220.

Geyman, E. C. and Maloof, A. C. (2019) 'A Simple Method for Extracting Water Depth From Multispectral Satellite Imagery in Regions of Variable Bottom Type', Earth and Space Science. doi: 10.1029/2018EA000539.

Gholamalifard, M. et al. (2013) 'Bathymetric modeling from satellite imagery via Single Band Algorithm (SBA) and Principal Components Analysis (PCA) in Southern Caspian Sea', International Journal of Environmental Research, 7(4), pp. 877-886.

Green, E. P. et al. (2000) Remote Sensing Handbook for Tropical Coastal Management, Coastal Management Sourcebooks 3.

Hamilton, M. K. et al. (1993) 'Estimating chlorophyll content and bathymetry of Lake Tahoe using AVIRIS data', Remote Sensing of Environment, 44(2-3), pp. 217-230.

Hartmann, K., Wettle, M. and Heege, T. (2017) 'The Increasing Importance of Satellite-derived Bathymetry' , GIM International. Available at: https://www.gim-international.com/content/article/the-increasingimportance-of-satellite-derived-bathymetry\#: :text=Bathymetric data in the shallow,zone management or hydrodynamic modelling.

Van Hengel, W. and Spitzer, D. (1991) 'Multi-temporal water depth mapping by means of Landsat TM' , International Journal of Remote Sensing, 12(4), pp. 703-712.

Ismail, M. R. (2007) Small Islands in North Halmahera Regency (Overview of the Management of Skipjack Fishery Resources), Thesis. Sekolah Pascasarjana IPB (Bogor Agricultural University). Available at: https://adoc.pub/kajian-pengembangan-wilayah-pulau-pulau-kecil-di-kabupaten-h.html.

Jawak, S. D. and Luis, A. J. (2015) ' 'Spectral information analysis for the semiautomatic derivation of shallow lake bathymetry using high-resolution multispectral imagery : A case study of Antarctic coastal oasis' , Aquatic Procedia, 4(Icwrcoe), pp. 1331-1338. doi: 10.1016/j.aqpro.2015.02.173.

Kanno, A. et al. (2013) 'Generalized Lyzenga' s Predictor of Shallow Water Depth for Multispectral Satellite Imagery’ , Marine Geodesy, 36(4), pp. 365-376. doi: 10.1080/01490419.2013.839974.

Kanno, A., Koibuchi, Y. and Isobe, M. (2011) 'Shallow Water Bathymetry from Multispectral Satellite Images: Extensions of Lyzenga' s Method for Improving Accuracy' , Coastal Engineering Journal, 53(4), pp. 431-450. doi: 10.1142/S0578563411002410.

Kumari, P. and Ramesh, H. (2020) 'Remote sensing image based nearshore bathymetry extraction of Mangaluru coast for planning coastal reservoir', in Sitharam, T. G. et al. (eds) Sustainable Water Resource Development Using Coastal Reservoirs. Oxford: Butterworth-Heinemann, pp. 247-265. doi: https://doi.org/10.1016/B978-0-12-818002-0.00013-7.

Lyzenga, D. R. (1978) 'Passive remote sensing techniques for mapping water depth and bottom features' , Applied Optics, 17(3), pp. 379-383. doi: 10.1364/AO.17.000379.

Lyzenga, D. R. (1981) 'Remote sensing of bottom reflectance and water attenuation parameters in shallow water using aircraft and Landsat data ( Bahamas).' , International Journal of Remote Sensing, 2(1), pp. $71-82$.

Manessa, M. D. M. et al. (2016) 'Satellite-Derived Bathymetry using Random Forest Algorithm and Worldview-2 Imagery' , Geoplanning: Journal of Geomatics and Planning; Vol 3, No 2 (2016): (October 2016)DO 10.14710/geoplanning.3.2.117-126.

Available

at: 
https://ejournal.undip.ac.id/index.php/geoplanning/article/view/12047.

Mateo-Pérez, V. et al. (2020) 'Port bathymetry mapping using support vector machine technique and sentinel2 satellite imagery’ , Remote Sensing. doi: 10.3390/rs12132069.

McLaren, K., McIntyre, K. and Prospere, K. (2019) 'Using the random forest algorithm to integrate hydroacoustic data with satellite images to improve the mapping of shallow nearshore benthic features in a marine protected area in Jamaica' , https://doi.org/10.1080/15481603.2019.1613803, 56(7), pp. 10651092. doi: 10.1080/15481603.2019.1613803.

Misra, A. et al. (2018) 'Shallow water bathymetry mapping using Support Vector Machine (SVM) technique and multispectral imagery' , International Journal of Remote Sensing, 39(13), pp. 4431-4450. doi: 10.1080/01431161.2017.1421796.

Pacheco, A. et al. (2015) 'Retrieval of nearshore bathymetry from Landsat 8 images: A tool for coastal monitoring in shallow waters', Remote Sensing of Environment, 159, pp. 102-116. doi: 10.1016/j.rse.2014.12.004.

Pattanaik, A., Sahu, K. and Bhutiyani, M. R. (2015) 'Estimation of Shallow Water Bathymetry Using IRSMultispectral Imagery of Odisha Coast, India' , Aquatic Procedia, 4, pp. 173-181. doi: https://doi.org/10.1016/j.aqpro.2015.02.024.

Philpot, W. D. (1989) 'Bathymetric mapping with passive multispectral imagery' , Applied Optics, 28(8), pp. 1569-1578. doi: 10.1364/AO.28.001569.

S. Halim, H. (2017) 'Gazing Coastal Ecotourism in Morotai Islands, Indonesia' , Environmental Management and Sustainable Development. doi: 10.5296/emsd.v6i2.11393.

Sagawa, T. et al. (2019) 'Satellite derived bathymetry using machine learning and multi-temporal satellite images’ , Remote Sensing. doi: 10.3390/rs11101155.

Siermann, J. et al. (2014) 'Satellite derived Bathymetry and Digital Elevation Models (DEM)' , International Petroleum Technology Conference. doi: 10.2523/IPTC-17346-MS.

Spitzer, D. and Dirks, R. W. J. (1987) 'Bottom influence on the reflectance of the sea.' , International Journal of Remote Sensing, 8(3), pp. 279-290.

Stumpf, R. P., Holderied, K. and Sinclair, M. (2003) 'Determination of water depth with high-resolution satellite imagery over variable bottom types’ , Limnology and Oceanography, 48(1part2), pp. 547-556. doi: 10.4319/lo.2003.48.1_part_2.0547.

Traganos, D. et al. (2018) 'Estimating satellite-derived bathymetry (SDB) with the Google Earth Engine and sentinel-2' , Remote Sensing. doi: 10.3390/rs10060859.

USGS (2015) 'Landsat 8 (L8) Data Users Handbook' , Earth Resources Observation and Science (EROS) Center.

USGS (2019) 'EarthExplorer - Home’ , U.S. Geological Survey.

Vinayaraj, P. (2017) 'Development of Algorithms for Near-shore Satellite Derived Bathymetry Using Multispectral Remote Sensing Images' , p. 1.

Vinayaraj, P., Raghavan, V. and Masumoto, S. (2016) 'Satellite-Derived Bathymetry using Adaptive Geographically Weighted Regression Model' , Marine Geodesy, 39(6), pp. 458-478. doi: 10.1080/01490419.2016.1245227.

Wijaya, S. W. et al. (2012) Pulau Morotai: Sumberdaya Strategis di Kawasan Timur Indonesia.

Wood, S. N. (2017) Generalized additive models: An introduction with $R$, second edition, Generalized Additive Models: An Introduction with R, Second Edition. doi: 10.1201/9781315370279.

Zhang, K. et al. (2021) 'Improving Statistical Uncertainty Estimate of Satellite-Derived Bathymetry by Accounting for Depth-Dependent Uncertainty' , IEEE Transactions on Geoscience and Remote Sensing, pp. 1-9. doi: 10.1109/TGRS.2021.3069868. 